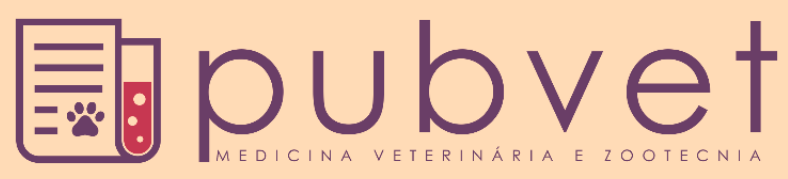

https://doi.org/10.31533/pubvet.v13n01a246.1-11

\title{
Mieloencefalite protozoária equina (Sarcocystis neurona e Neospora hughesi): Revisão
}

\author{
Severino Ernesto Rezende Vilela ${ }^{1}$, Priscila Gomes de Oliveira $^{2}{ }^{\bullet}$, Cecília Nunes \\ Moreira $^{3 \bullet}$, Klaus Casaro Saturnino ${ }^{3}$, Marco Antônio de Oliveira Viu ${ }^{3}{ }^{\bullet}$, Débora da \\ Silva Freitas Ribeiro ${ }^{4} \bullet$, Dirceu Guilherme de Souza Ramos $^{3 * \bullet}$
}

${ }^{1}$ Discente do curso de Medicina Veterinária do Centro Universitário de Mineiros, Mineiros, Goiás, Brasil. ${ }^{2}$ Médica Veterinária e Técnica do Laboratório de Análises Clínicas Veterinárias do Hospital Veterinário da Universidade Federal de Goiás - Regional Jataí. ${ }^{3}$ Professor(a) do curso de Medicina Veterinária da Universidade Federal de Goiás, Regional Jataí, Departamento de Medicina Veterinária, Jataí, Goiás, Brasil. ${ }^{4}$ Professora do curso de Medicina Veterinária do Centro Universitário de Mineiros, Mineiros, Goiás, Brasil. E-mail:

*Autor para correspondência, E-mail: dgramos_vet@hotmail.com

\begin{abstract}
Resumo. A Mieloencefalite Protozoária Equina é uma doença que acomete os equinos e asininos pela ocorrência e formação de cistos na medula espinhal e sistema nervoso central de merozoítos de Sarcocystis neurona e Neospora hughesi. De maneira geral, equinos são hospedeiros intermediários acidentais de $S$. neurona quando ingerem oocistos liberados nas fezes de gambás (Didelphis spp.) que são os hospedeiros definitivos. Embora a ocorrência e associação da doença já tenham sido feita com $N$. hughesi, a biologia e transmissão do agente não são totalmente esclarecidos, embora devam se assemelhar a Neospora caninum. O quadro clínico em equinos cursa com sintomatologia de ordem neurológica e o prognóstico não é favorável. Alguns casos da doença já foram descobertos na mesorregião do Sudoeste Goiano, embora os dados não tenham sido publicados, o que tem chamado a atenção de médicos veterinários e pesquisadores da região. Sendo assim, o objetivo deste trabalho de conclusão de curso é fazer uma revisão sobre a Mieloencefalite Protozoária Equina, explicando aspectos de etiologia, biologia, epidemiologia, patogenia, sinais clínicos, diagnóstico, tratamento e prevenção da doença.
\end{abstract}

Palavras chave: Encefalomielite, epidemiologia, neosporose, parasitismo, sarcosporidiose

\section{Equine protozoal myeloencephalitis (Sarcocystis neurona and Neospora hughesi): Review}

\begin{abstract}
Equine Protozoal Mieloencephalitis is a disease that affects equines and asininos by the occurrence and formation of cysts in the spinal cord and central nervous system of merozoites of Sarcocystis neurona and Neospora hughesi. In general, horses are accidental intermediate hosts of $S$. neurona when they ingest oocysts released in the skunks of the opossums (Didelphis spp.), Which are the definitive hosts. Although the occurrence and association of the disease has already been made with $N$. hughesi, the biology and transmission of the agent are not fully understood, although they should resemble Neospora caninum. The clinical picture in horses presents with neurological symptomatology and the prognosis is not favorable. Some cases of the disease have already been discovered in the south-western Goiás mesoregion, although the data have not been published, which has drawn the attention of veterinarians and researchers in the region. Therefore, the objective of this work is to review the Protozoan Equine Myeloencephalitis, explaining aspects of etiology, biology, epidemiology, pathogenesis, clinical signs, diagnosis, treatment and prevention of the disease.
\end{abstract}

Keywords: Encephalomyelitis, epidemiology, neosporosis, parasitism, sarcosporidiosis 


\title{
Mieloencefalitis protozoaria equina (Sarcocystis neurona y Neospora hughesi): Revisión
}

\begin{abstract}
Resumen. La Mieloencefalitis Protozoaria Equina es una enfermedad que acomete equinos y asininos por la incidencia y formación de quistes en la médula espinal y sistema nervioso central de merozoítos de Sarcocystis neurona y Neospora hughesi. En general, los equinos son hospedadores intermedios accidentales de $S$. neurona cuando ingieren oocistos liberados en las heces de faras (Didelphis spp.) Que son los hospederos definitivos. Aunque la incidencia y asociación de la enfermedad ya se ha hecho con $N$. hughesi, la biología y la transmisión del agente no están totalmente claras, sin embargo, deben asemejarse a la Neospora caninum. El cuadro clínico en equinos cursa con sintomatología de orden neurológico y el pronóstico no es favorable. Algunos casos de la enfermedad ya fueron descubiertos en la mesorregión del Sudoeste de Goiás, no obstante, los datos no se publicaron, lo que ha llamado la atención de médicos veterinarios e investigadores de la región. Por tanto, el objetivo de este trabajo de conclusión de curso es hacer una revisión sobre la Mieloencefalitis Protozoaria Equina, explicando aspectos de etiología, biología, epidemiología, patogenia, signos clínicos, diagnóstico, tratamiento y prevención de la enfermedad.
\end{abstract}

Palabras clave: Encefalomielitis, epidemiología, neosporosis, parasitismo, sarcosporidiosis

\section{Introdução}

A Mieloencefalite Protozoária Equina (MPE), também conhecida como Encefalomielite Protozoária Equina, ou ainda Equine Protozoal Myeloencenphalitis é uma doença neurológica importante que acomete equinos e asininos nas Américas. O protozoário comumente descrito como agente etiológico da doença é o Sarcocystis neurona, muito embora desde a década de 90 do século XX, Neospora hughesi tem sido apontado como agente causador do mesmo tipo de lesão nos animais (Dubey et al., 2001d).

A priori Sarcosporidioses (doenças causadas por espécies de Sarcocystis spp., do grego: sarx-carne + kystis-vesícula, cisto) foram descritas como casos de Toxoplasmose, pelo fato de formarem cistos em tecidos do hospedeiro intermediário e se desenvolverem no tecido epitelial do intestino dos hospedeiros definitivo, tal como ocorre com Toxoplasma spp. A própria MPE, ainda mais pelo acometimento do sistema nervoso já foi chamada de Toxoplasmose Equina, tamanha semelhança entre as formas morfológicas, ciclo biológicos e meios de transmissões. Entretanto, dentro do mesmo grupo de coccídeos que se desenvolvem dentro destas características temos atualmente o conhecimento a respeito da família Sarcocystidae com sete gêneros, sendo três mais comuns e com maior importância em medicina veterinária de animais domésticos: Toxoplasma, Sarcocystis e Neospora (Roskov et al., 2013).

Para S. neurona os hospedeiros definitivos são gambás que se alimentam de carne dos hospedeiros intermediários contendo cistos. Na América do Norte, especificamente, o Didelphis virginiana e na América do Sul preferencialmente Didelphis albiventris, mas outras espécies de gambás podem estar envolvidas também. Em todas as espécies ocorre o desenvolvimento do parasita em células do epitélio intestinal e serão liberados oocistos que infectarão os hospedeiros intermediários (Dubey et al., 2015). Os hospedeiros intermediários naturais são tatus, guaxinins, "skunks" ou como são popularmente conhecidos "gambás de listras" e felinos silvestres, onde como dito anteriormente, ocorrerá o desenvolvimento de cistos na musculatura esquelética quando os hospedeiros intermediários ingerirem água ou alimentos contaminados com oocistos liberados nas fezes de gambás (Howe et al., 2014). Quando equinos ingerem os mesmos oocistos do ambiente, os esporozoítos ao invés de irem para a musculatura esquelética migram preferencialmente para a medula espinhal, Sistema Nervoso Central (SNC) e em raros casos para musculatura cardíaca, sendo considerados como hospedeiros intermediários acidentais (Dubey et al., 2015).

A biologia e ocorrência de $N$. hughesi ainda não são totalmente conhecidas pela ciência, existindo poucos relatos, mas que trazem o parasito como agente emergente e considerado como agente etiológico da MPE (Reed et al., 2016). A doença tem maior importância pelos danos causados a equinos, 
especialmente quando da formação de cistos na medula espinhal, onde os sinais clínicos serão de ordem neurológica e terão prognóstico desfavorável.

O objetivo deste trabalho é fazer uma revisão sobre a Mieloencefalite Protozoária Equina, desde a descrição de seus agentes etiológicos, até as formas de ocorrência, sinais clínicos, tratamento e prevenção, uma vez que casos da doença já foram encontrados na mesorregião do Sudoeste Goian e tem sido alvo de preocupações e estudos de pesquisadores do Centro Universitário de Mineiros (UNIFIMES), bem como de outras instituições presentes na mesma mesorregião.

\section{Histórico e etiologia}

A Mieloencefalite Protozoária Equina foi descrita pela primeira vez por Rooney et al. (1970), como mielite segmental e posteriormente como encefalomielite focal, devido ao envolvimento de lesões cerebrais. Essa primeira descrição ocorreu no encontro da American Association of Equine Practitioners (AAEP) quando foram relatados 52 casos da doença pelos autores citados. Prickett (1968) já havia relatado 44 casos anteriormente com sintomas semelhantes, porém não houve uma descrição nominal da enfermidade. Em 1974 foi observada pela primeira vez a presença de protozoários em lesões características da doença primariamente associada ao gênero Toxoplasma (Beech \& Dodd, 1974; Cusick et al., 1974) e a doença ganhou o nome que conhecemos hoje de Mieloencefalite Protozoária Equina (MPE) com o relato de 45 casos por Mayhew (1976).

O protozoário Sarcocystis neurona é apontado como principal agente etiológico da doença (Reed et al., 2016), embora atualmente dois agentes sejam apontados na literatura como responsáveis pela ocorrência da doença: S. neurona (Dubey et al., 1991) e N. hughesi (Cheadle et al., 1999; Dubey et al., 2001a; Hamir et al., 1998; Marsh et al., 1996). O histórico científico da doença é mais bem observado na Tabela 1.

Tabela 1. Histórico científico da Mieloencefalite Protozoária Equina.

\begin{tabular}{|c|c|}
\hline Contribuição Científica & Referência \\
\hline Síndrome clínica reconhecida, mas sem agente etiológico definido & Rooney et al. (1970) \\
\hline Protozoário é associado a lesão pela primeira vez & $\begin{array}{l}\text { Beech \& Dodd (1974) e } \\
\text { Cusick et al. (1974) }\end{array}$ \\
\hline O nome Mieloencefalite Protozoária Equina é utilizado pela primeira vez e é instituída a quimioterapia & Mayhew (1976) \\
\hline Sarcocystis é apontado como agente etiológico da doença & Dubey (1976) \\
\hline Protozoário é isolado em cultivo celular e nomeado $S$. neurona & Dubey et al. (1991) \\
\hline Gambás (Didelphis virginiana) são propostos como hospedeiros definitivos do $S$. neurona & Fenger et al. (1995) \\
\hline Neospora hughesi também é apontado como agente etiológico da doença & Marsh et al. (1996) \\
\hline Síndrome clínica é descrita em animais submetidos a ingestão de esporocistos provenientes de gambás & Fenger et al. (1997a) \\
\hline Gambás (D. virginiana) provam ser os hospedeiros definitivos capaz de induzir a doença & Dubey \& Lindsay (1998) \\
\hline S. neurona é isolado de Sistema Nervoso Central de hospedeiro não equino & Lindsay et al. (2000) \\
\hline S. neurona é descrito definitivamente e tem seu ciclo biológico completamente elucidado & Dubey et al. (2000) \\
\hline Gambá da América do Sul (D. albiventris) é descrito como hospedeiro definitivo para S. neurona no Brasil & Dubey et al. (2001b) \\
\hline
\end{tabular}

Adaptado de Dubey et al. (2001c)

Os esquizontes e "sarcocistos" de S. neurona são os estágios encontrados nos tecidos do equino quando o mesmo funciona como hospedeiro intermediário do $S$. neurona, sendo que nos hospedeiros intermediários naturais os esquizontes e sarcocistos estarão presentes no tecido muscular. Equinos quando naturalmente infectados apresentarão danos e lesões no Sistema Nervoso Central, especialmente na medula espinhal (Dubey et al., 2001e), onde tanto células neurais como células de infiltrados inflamatórios podem ser parasitadas por centenas de merozoítos (Reed et al., 2016). Os esquizontes possuem núcleo lobulado, onde serão divididos e surgirão os merozoítos. Vários esquizontes em diferentes estágios de desenvolvimento podem ser encontrados em uma única célula, e é o seu desenvolvimento que provocará o surgimento dos sinais clínicos e que apesar de apresentar diferentes estágios de maturação, morfologicamente serão semelhantes. Esquizontes maduros parasitando células da medula espinhal terão até $30 \mu \mathrm{m}$ de comprimento, com formato ovalado, alongados e irregulares, já os merozoítos que se formam dentro dos mesmos apresentarão dimensões de até 7-8 $\mu \mathrm{m} \times 1-2 \mu \mathrm{m}$, 
sendo que organelas estarão presentes somente dentro dos merozoítos e incluem todas as organelas de qualquer célula eucariota, e além destas apresentarão também as róptrias, que são organelas de particular importância no desenvolvimento de coccídeos (Speer \& Dubey, 2001). De maneira geral somente esquizontes e sarcocistos de $S$. neurona podem ser encontrados em equinos produzindo um número elevado de merozoítos através de reprodução assexuada no processo de esquizogonia. Os merozoítos podem se diferenciar novamente em esquizontes gerando novos merozoítos pelo mesmo processo e o número de vezes que essa repetição pode ocorrer nesses hospedeiros ainda não foi esclarecido, sendo que estes tipos celulares podem ser encontrados em medula espinhal (maioria dos casos) e células cardíacas (alguns relatos de infecção experimental já foram registrados) (Dubey et al., 2015).

$\mathrm{O} N$. hughesi tem morfologia similar quando encontrado nos hospedeiros intermediários, e apesar de sua relação com a Mieloencefalite Protozoária Equina ser datada da década de 90 ainda no século XX, poucos registros são encontrados considerando este agente etiológico, primeiro pelo fato de sua transmissão para equinos não estar bem esclarecida, incluindo o fato de que nem mesmo seus hospedeiros definitivos ainda estarem cientificamente definidos e também por possivelmente ter sido confundido com $S$. neurona até o surgimento de técnicas moleculares de diagnóstico serem utilizadas para o sequenciamento de agentes envolvidos nos casos de animais acometidos pela doença (Howe et al., 2014).

\section{Biologia}

\section{Sarcocystis neurona}

Sarcocystis neurona possui um ciclo biológico com dois hospedeiros como mencionado anteriormente, um definitivo e um intermediário. De maneira geral espécies do gênero Sarcocystis possuem um ciclo comum a maioria dos coccídeos, dividido assim em três partes: esporogonia, esquizogonia (ou merogonia) e gametogonia, sendo a última parte a fase de reprodução sexuada e as demais de reprodução assexuada. A gametogonia destas espécies ocorrem no intestino delgado do hospedeiro definitivo, esporogonia no ambiente e esquizogonia nos tecidos musculares dos hospedeiros intermediários na maioria dos casos (Howe et al., 2014).

Para S. neurona atuam como hospedeiros definitivos espécies de gambás, na América do Norte especificamente o Didelphis virginiana (Fenger et al., 1995) e na América do Sul preferencialmente Didelphis albiventris, mas outras espécies de gambás podem estar envolvidas também (Dubey et al., 2001b). Nestes hospedeiros ocorre o desenvolvimento da gametogonia, onde pela ingestão de tecido do hospedeiro intermediário contendo merozoítos o gambá se torna infectado, a partir daí os merozoítos liberados no intestino do hospedeiro definitivo penetram em células epiteliais se transformando em macrogametas ou microgametas (a diferenciação é aleatória e espontânea). Microgametas são liberados da célula parasitada e fecundam os macrogametas adjacentes formando um oocisto que será eliminado nas fezes (Howe et al., 2014). No ambiente serão formados pela reprodução assexuada vários esporozoítos dentro do oocisto, processo que recebe o nome de esporogonia. Estes oocistos esporulados serão as formas infectantes do hospedeiro intermediário que ingerirão os mesmos ao ingerir alimentos ou água contaminados (Howe et al., 2014). Naturalmente os hospedeiros intermediários de S. neurona são tatus (Cheadle et al., 2001), guaxinins (Dubey et al., 2001f), "skunks" ou como são popularmente conhecidos "gambás de listras" (Cheadle et al., 2001) e felinos silvestres (Dubey et al., 2000). Nos hospedeiros intermediários naturais os esporozoítos se liberarão do oocisto e através da corrente sanguínea chegarão a musculatura onde se transformarão em esquizontes gerando merozoítos, portanto, no tecido muscular esquelético (Howe et al., 2014). Quando equinos ingerem os mesmos oocistos do ambiente, os esporozoítos ao invés de irem para a musculatura esquelética migram preferencialmente para a medula espinhal, Sistema Nervoso Central (SNC) e em raros casos para musculatura cardíaca, sendo considerados como hospedeiros intermediários acidentais (Dubey et al., 2015).

\section{Neospora hughesi}

O ciclo biológico de $N$. hughesi não é conhecido completamente, visto que se trata de um parasita emergente, descoberto a não muito tempo associado à Mieloencefalite Protozoária Equina, e o modo como ocorre sua transmissão para equinos não é totalmente esclarecido (Howe et al., 2014; Reed et al., 
2016). Possivelmente seu ciclo deve se assemelhar com o Neospora caninum que tem canídeos como hospedeiros definitivos onde se desenvolvem no epitélio intestinal nos mesmo estágio que o $S$. neurona, mas não se pode afirmar que os mesmos hospedeiros são parasitados por $N$. hughesi (McAllister et al., 1998). Entretanto, assim como ocorre transmissão vertical (da mãe para o filhote) em N. caninum, alguns estudos têm apontado que o mesmo ocorre para N. hughesi (Antonello et al., 2012; Pusterla et al., 2011).

\section{Epidemiologia e fatores de risco}

O primeiro estudo epidemiológico sobre a MPE foi realizado nos Estados Unidos e Canadá por Fayer et al. (1990) usando dados de análises post-mortem de dez centros de diagnóstico que concentravam a maior quantidade de diagnósticos da doença até então. Os dados analisados mostraram que $61,8 \%$ das ocorrências em equinos eram em animais com até quatro anos de idade, e 19,8\% em animais com oito anos ou mais e o restante na faixa etária intermediária. Sendo assim animais mais jovens são mais acometidos, e um estudo do mesmo ano propôs que a idade em que os animais estão mais suscetíveis à ocorrência da doença varia entre 0,8 e 6,4 anos de idade (Boy et al., 1990).

Com relação à soroprevalência para $S$. neurona (número de animais que possuem anticorpos e, portanto, já entraram em contato com o agente etiológico) nos Estados Unidos existe uma grande variação, onde foram registradas soroprevalências de $15 \%$ e em maiores ocorrências chegando a $89 \%$ dos animais dependendo da região do território americano (Bentz et al., 2003; Bentz et al., 1997; Blythe et al., 1997; Saville et al., 1997; Tillotson et al., 1999). No Brasil apenas um estudo apontou soroprevalência de $S$. neurona em equinos apontando 35,6\% de animais com anticorpos para o agente (Dubey et al., 1999a) e na Argentina apontou 35,5\% dos animais com a presença de anticorpos para esta espécie de parasita (Dubey et al., 1999b), evidenciando uma distribuição equivalente da doença pela América do Sul até então.

Quando consideramos a soro prevalência encontrada para $N$. hughesi, como se trata de um agente emergente, poucos estudos ainda relacionam aspectos epidemiológicos e prevalência e, portanto, poucos estudos apontam soro prevalências maiores que 10\% nos animais (Bártová et al., 2010; Cheadle et al., 1999; Dubey et al., 2003; Pitel et al., 2001; Vardeleon et al., 2001; Villalobos et al., 2012) em algumas regiões geográficas, sendo frequentemente apontadas soroprevalências menores que 3\% (Dangoudoubiyam et al., 2011; Dubey et al., 1999a; Dubey et al., 1999b; Gupta et al., 2002; Hoane et al., 2006; Hoane et al., 2005). Essas variações são decorrentes principalmente de diferenças geográficas, mas também tem sido considerada a possibilidade de a ocorrência estar sendo subestimada pela baixa sensibilidade das análises atualmente disponíveis (Dangoudoubiyam et al., 2011; Hoane et al., 2005; Vardeleon et al., 2001).

Independente do agente envolvido estima-se que a incidência da MPE em equinos seja entre 8-20 novos casos a cada 10.000 animais anualmente (NAHMS, 2001). Pode-se desta maneira considerar a MPE uma doença esporádica de casos isolados ou ainda de pequenos focos (Fenger et al., 1997b; Granstrom et al., 1992). Deve-se ressaltar que apesar da idade de maior risco estipulada por Boy et al. (1990) e citada anteriormente, são considerados animais com maior risco de ocorrência da MPE atualmente, animais que estão entre 1-5 anos de idade e acima de 13 anos de idade (Saville et al., 2000b). Considerando aspectos sazonais, a doença ocorre em menor quantidade no inverno, com risco três vezes maior na primavera e no verão, e seis vezes maior no outono, que é, portanto, a estação de maior ocorrência. Esta sazonalidade está relacionada diretamente com a biologia do hospedeiro definitivo que são gambás. De maneira geral, no inverno espécies de Didelphis tem menor atividade no inverno, em alguns casos entrando inclusive em estado de hipobiose (hibernação) e consequentemente dispersarão menos oocistos no ambiente durante o período de inverno. Durante a primavera e no verão tem o aumento de sua atividade, até que no outono acabam ingerindo uma grande quantidade de alimento (e defecando mais oocistos no ambiente consequentemente), pois, precisarão de uma boa reserva energética para o próximo inverno.

A presença de gambás em um ambiente de criação de equinos aumenta o risco de ocorrência da doença 2,5 vezes mais, assim como áreas arborizadas também representam fator de risco de ocorrência da doença 2 vezes maior do que em áreas não arborizadas, já que gambás preferem áreas com cobertura arbórea. Esses pequenos marsupiais tendem a se aproximar de áreas de criação devido a disponibilidade 
de alimento, tornando importante hábitos de higiene animal para o controle da doença, como fornecimento regulado de ração e limpeza constante das instalações (Reed et al., 2016).

De acordo com Saville et al. (2000a), se há o impedimento que animais selvagens tenham acesso a alimentação ou a água fornecida aos equinos, o risco de ocorrência da MPE reduz para um terço da probabilidade. Cavalos de provas, apresentações, ou submetidos a outras situações de estresse, como exercícios pesados, transporte, cirurgias, tratamentos prolongados são mais suscetíveis á ocorrência de MPE de acordo com o mesmo trabalho. O mesmo estudo ainda apontou que animais tratados periodicamente com anti-coccidianos têm dez vezes menos probabilidade de desenvolvimento de sinais clínicos da MPE.

\section{Patogenia}

Considerando as soroprevalências encontradas é necessário estabelecer alguns aspectos relacionados com a patogenia, isso porque o número de animais que apresentam anticorpos para $S$. neurona e $N$. hughesi, não é igual ao número de animais que apresentam a doença clínica, ou seja, nem todos os animais infectados com o parasita necessariamente apresentarão sintomas causados pelos mesmos (Howe et al., 2014). Ainda segundo Howe et al. (2014) embora equinos de maneira geral sejam considerados susceptíveis, a doença clínica não se desenvolve em todos os animais infectados, e infelizmente os conhecimentos científicos atuais não deixam claro como a doença evolui de um quadro assintomático para um quadro neurológico severo, o que pode dificultar o diagnóstico e consequentemente o tratamento, controle e prevenção da doença.

Possivelmente situações de estresse ou ainda que possam levar a imunossupressão podem acarretar no agravamento do quadro clínico e na apresentação de danos neurológicos (Saville et al., 2000a; Saville et al., 2001) conforme mencionado, entretanto estudos que tentaram induzir situações de estresse ou ainda utilizar drogas imunossupressoras em animais infectados não observaram agravamento do quadro clínico, demonstrando que a relação entre imunossupressão e ocorrência de MPE é mais complexa (Cutler et al., 2001; Saville et al., 2004). Estudos genéticos e antigênicos com isolados de S. neurona demonstraram que existem variações, sugerindo que existam cepas mais virulentas que outras capazes de desenvolver os quadros neurológicos (Wendte et al., 2010). A patogenia de $N$. hughesi, é menos conhecida ainda, sendo de consenso científico que são necessários mais estudos até que a patogenia da MPE seja explicada, independente do agente etiológico envolvido (Howe et al., 2014).

\section{Sinais clínicos}

Os sinais clínicos da MPE irão variar de acordo com o local da lesão (cérebro, cerebelo ou ainda medula espinhal). Inicialmente os animais irão apresentar disfagia, funcionamento anormal do sistema respiratório, claudicação e até mesmo convulsões. Com o agravamento do quadro, alguns cavalos podem apresentar dificuldade de ficar em pé, andar ou engolir. A doença pode progredir rapidamente, sendo que alguns animais podem até apresentar uma discreta melhora, porém podem agravar os sintomas novamente mais tarde (Reed et al., 2016). A variabilidade das lesões está relacionada com a infecção e formação de cistos em múltiplos locais do Sistema Nervoso Central (Reed et al., 2016). Quando ocorre a infecção de massa cinzenta os sinais apresentados geralmente são atrofia muscular focal e fraqueza severa, enquanto danos à substância branca apresentarão quadros de ataxia, e fraqueza nos membros caudais ao local da lesão. Tropeços e descoordenações frequentes com alternância de membros ("trançar de pernas") podem estar presentes e serem confundidos com claudicação. O último estágio da doença é quando o animal incapaz de se locomover apresenta-se em decúbito (Reed et al., 2016). Animais com MPE, mesmo com quadro neurológico instalado, apresentarão sinais vitais normais, dispostos e alertas. Áreas de hiporreflexia, hiperalgesia ou perda sensorial completa podem estar evidentes. Inclinação de cabeça, paralisia do nervo facial e dificuldade de engolir também são recorrentes (Granstrom et al., 1992; Reed et al., 2016).

\section{Diagnóstico}

Em áreas que compreendem o nicho de desenvolvimento de Didelphis spp., equinos que possuam sintomas de doença neurológica devem ter MPE como suspeita. Deve ser realizado exame neurológico completo, onde a assimetria de marcha e atrofia muscular focal pode indicar MPE. Exames laboratoriais 
devem ser realizados para confirmar a suspeita e eliminar hipóteses (Howe et al., 2014). Entre as doenças que servem de diagnóstico diferencial estão a Mielopatia Estenótica Vertebral Cervical (MEVC), que não apresenta atrofia muscular (Reed et al., 2016). Em MEVC os sinais são sempre simétricos, e membros pélvicos são amplamente mais afetados que os torácicos. Howe et al. (2014) ressaltam que os sinais iniciais podem ser confundidos também com doença causada por Herpesvírus Equino do tipo I (EHV-1), onde os sinais também se apresentarão simétricos, e além do quadro neurológico, os animais acometidos por EHV-1apresentarão aborto, febre, distensão de bexiga urinária sem incontinência, dificuldade em defecar e paralisia de cauda. Doença Neurológica Motora Equina também tem sinais iniciais semelhantes, entretanto tremores e espasmos musculares servem para diferenciar os quadros clínicos (Reed et al., 2016).

O diagnóstico preciso pode ser realizado pela análise post-mortem, onde serão evidentes as lesões de SNC. Para o diagnóstico em animais vivos pode ser realizada ELISA e Western Blot para N. hughesi (Hoane et al., 2005) e Reação de Imuno fluorescência Indireta e Western Blot para S. neurona (Duarte et al., 2004).

\section{Tratamento e prevenção}

De acordo com Reed et al. (2016) os tratamentos aprovados e recomendados para MPE são: a) Ponazuril (dose recomendada $5-10 \mathrm{mg} / \mathrm{kg}$, frequência de utilização $24 / 24$ horas, via oral, duração do tratamento 4 semanas); b) Diclazuril (dose recomendada $2,5 \mathrm{mg} / \mathrm{kg}$, frequência de utilização 12/12 horas, via oral, duração do tratamento mínimo 21 dias); e c) Sulfadiazina + Pirimetamina (Sulfadiazina dose de $20 \mathrm{mg} / \mathrm{kg}$, frequência de utilização 24/24 horas, via oral, duração do tratamento 5 a 7 dias; associado à pirimetamina $1 \mathrm{mg} / \mathrm{kg}$, frequência de utilização 24/24 horas, via oral, duração de tratamento 90-120 dias). Além destes os tratamentos de suporte baseados na severidade dos sinais neurológicos e nas complicações apresentadas, devem ser realizados, especialmente fluidoterapia por via venosa, com solução fisiológica, dependerá do estado físico geral do animal, do grau de desidratação do animal, a quantidade dependerá. Também é utilizado na fluidoterapia antinflamatório não esteroidal (AINE), descrito preferencialmente o Flunixin Meglumine (dose recomendada $1,1 \mathrm{mg} / \mathrm{kg}$, via parenteral, duração do tratamento equinos: máximo 5 dias frequência de utilização 24/24 horas

A prevenção da doença passa por medidas como evitar o estresse e exposição a fezes de gambás. Abordagens práticas, como não deixar os animais se alimentarem no solo, deve-se fornecer fontes separadas de água potável para cavalos e impedir o acesso de animais selvagens a pastos, piquetes e barracas de equinos também podem ajudar a reduzir a incidência de infecções por protozoários em cavalos. Por último pode ser considerado o uso intermitente de drogas coccidiostáticas e coccidicidas para controle da MPE (Reed et al., 2016).

\section{Considerações finais}

De maneira geral pode-se considerar que a Mieloencefalite Protozoária Equina é uma doença grave, com sintomatologia nervosa causada por Sarcocystis neurona e Neospora hughesi. Nem todos os animais acometidos pelo parasita apresentarão o quadro clínico, que geralmente ocorrerá em situações de estresse e/ou imunossupressão.

Quadros neurológicos devem ter sempre como suspeita da doença que possui diagnóstico diferencial com outras doenças de ordem neurológica como Mielopatias, Doenças Motoras e ainda infecções virais (EHV-1) principalmente. O tratamento é bastante específico com utilização de drogas coccidiostáticas ou coccidiocidas, auxiliadas por tratamento com anti-inflamatórios não esteroidais para controle dos sintomas neurológicos.

Uma vez acometidos pela doença neurológica, o quadro pode ser agravado severamente, tendo um prognóstico reservado, pelo qual as formas de prevenção devem ser consideradas para a não ocorrência da doença. Deve-se, portanto, evitar situações de estresse e imunossupressão que possam desencadear a sintomatologia nervosa, especialmente se os animais forem criados em áreas onde estejam presentes gambás, que são os hospedeiros definitivos do S. neurona, servindo de fonte de infecção para os equinos, através da eliminação de oocistos em suas fezes. 
Vários aspectos relacionados a doença ainda não são esclarecidos atualmente, como a própria biologia do $N$. hughesi, entre outros fatores. Possivelmente novos estudos continuarão a ser realizados, trazendo uma necessidade de constante atualização para profissionais que forem trabalhar com a clínica de equinos.

\section{Referências bibliográficas}

Antonello, A. M., Pivoto, F. L., Camillo, G., Braunig, P., Sangioni, L. A., Pompermayer, E. \& Vogel, F. S. F. (2012). The importance of vertical transmission of Neospora sp. in naturally infected horses. Veterinary Parasitology, 187(3-4), 367-370.

Bártová, E., Sedlák, K., Syrová, M. \& Literák, I. (2010). Neospora spp. and Toxoplasma gondii antibodies in horses in the Czech Republic. Parasitology Research, 107(4), 783-785.

Beech, J. \& Dodd, D. C. (1974). Toxoplasma-like encephalomyelitis in the horse. Veterinary Pathology, 11(1), 87-96.

Bentz, B. G., Ealey, K. A., Morrow, J., Claypool, P. L. \& Saliki, J. T. (2003). Seroprevalence of antibodies to Sarcocystis neurona in equids residing in Oklahoma. Journal of Veterinary Diagnostic Investigation, 15(6), 597-600.

Bentz, B. G., Granstrom, D. E. \& Stamper, S. (1997). Seroprevalence of antibodies to Sarcocystis neurona in horses residing in a county of southeastern Pennsylvania. Journal of the American Veterinary Medical Association, 210(4), 517-518.

Blythe, L. L., Granstrom, D. E., Hansen, D. E., Walker, L. L., Bartlett, J. \& Stamper, S. (1997). Seroprevalence of antibodies to Sarcocystis neurona in horses residing in Oregon. Journal of the American Veterinary Medical Association, 210(4), 525-527.

Boy, M. G., Galligan, D. T. \& Divers, T. J. (1990). Protozoal encephalomyelitis in horses: 82 cases (1972-1986). Journal of the American Veterinary Medical Association, 196(4), 632-634.

Cheadle, M. A., Lindsay, D. S., Rowe, S., Dykstra, C. C., Williams, M. A., Spencer, J. A., Rolsma, M. D. (1999). Prevalence of antibodies to Neospora sp. in horses from Alabama and characterisation of an isolate recovered from a naturally infected horse. International Journal for Parasitology, 29, 1537-1543.

Cheadle, M. A., Tanhauser, S. M., Dame, J. B., Sellon, D. C., Hines, M., Ginn, P. E., Greiner, E. C. (2001). The nine-banded armadillo (Dasypus novemcinctus) is an intermediate host for Sarcocystis neurona. International Journal for Parasitology, 31(4), 330-335.

Cusick, P. K., Sells, D. M., Hamilton, D. P. \& Hardenbrook, H. J. (1974). Toxoplasmosis in two horses. Journal of the American Veterinary Medical Association, 164(1), 77-80.

Cutler, T. J., MacKay, R. J., Ginn, P. E., Gillis, K., Tanhauser, S. M., LeRay, E. V., Greiner, E. C. (2001). Immunoconversion against Sarcocystis neurona in normal and dexamethasone-treated horses challenged with S. neurona sporocysts. Veterinary Parasitology, 95(2-4), 197-210.

Dangoudoubiyam, S., Oliveira, J. B., Viquez, C., Gómez-García, A., González, O., Romero, J. J., Howe, D. K. (2011). Detection of antibodies against Sarcocystis neurona, Neospora spp., and Toxoplasma gondii in horses from Costa Rica. Journal of Parasitology, 97(3), 522-524.

Duarte, P. C., Daft, B. M., Conrad, P. A., Packham, A. E., Saville, W. J., MacKay, R. J., Reed, S. M. (2004). Evaluation and comparison of an indirect fluorescent antibody test for detection of antibodies to Sarcocystis neurona, using serum and cerebrospinal fluid of naturally and experimentally infected, and vaccinated horses. Journal of Parasitology, 90(2), 379-386.

Dubey, J. P. (1976). A review of Sarcocystis of domestic animals and of other coccidia of cats and dogs. Journal of the American Veterinary Medical Association, 169(10), 1061-1078.

Dubey, J. P., Davis, S. W., Speer, C. A., Bowman, D. D., De Lahunta, A., Granstrom, D. E., Suter, M. M. (1991). Sarcocystis neurona n. sp.(Protozoa: Apicomplexa), the etiologic agent of equine protozoal myeloencephalitis. The Journal of parasitology, 212-218.

Dubey, J. P., Howe, D. K., Furr, M., Saville, W. J., Marsh, A. E., Reed, S. M. \& Grigg, M. E. (2015). An update on Sarcocystis neurona infections in animals and equine protozoal myeloencephalitis (EPM). Veterinary Parasitology, 209(1-2), 1-42. 
Dubey, J. P., Kerber, C. E. \& Granstrom, D. E. (1999a). Serologic prevalence of Sarcocystis neurona, Toxoplasma gondii, and Neospora caninum in horses in Brazil. Journal of the American Veterinary Medical Association, 215(7), 970-972.

Dubey, J. P., Liddell, S., Mattson, D., Speer, C. A., Howe, D. K. \& Jenkins, M. C. (2001a). Characterization of the Oregon isolate of Neospora hughesi from a horse. Journal of Parasitology, 87(2), 345-353.

Dubey, J. P. \& Lindsay, D. S. (1998). Isolation in immunodeficient mice of Sarcocystis neurona from opossum (Didelphis virginiana) faeces, and its differentiation from Sarcocystis falcatula. International Journal for Parasitology, 28(12), 1823-1828.

Dubey, J. P., Lindsay, D. S., Kerber, C. E., Kasai, N., Pena, H. F. J., Gennari, S. M., Rosenthal, B. M. (2001b). First isolation of Sarcocystis neurona from the South American opossum, Didelphis albiventris, from Brazil. Veterinary Parasitology, 95(2-4), 295-304.

Dubey, J. P., Lindsay, D. S., Saville, W. J. A., Reed, S., Granstrom, D. E. \& Speer, C. A. (2001c). A review of Sarcocystis neurona and equine protozoal myeloencephalitis (EPM). Veterinary Parasitology, 95(2-4), 89-131.

Dubey, J. P., Lindsay, D. S., Saville, W. J. A., Reed, S. M., Granstrom, D. E. \& Speer, C. A. (2001d). A review of Sarcocystis neurona and equine protozoal myeloencephalitis (EPM). Veterinary Parasitology, 95(2), 89-131.

Dubey, J. P., Mattson, D. E., Speer, C. A., Hamir, A. N., Lindsay, D. S., Rosenthal, B. M., Tornquist, S. J. (2001e). Characteristics of a recent isolate of Sarcocystis neurona (SN7) from a horse and loss of pathogenicity of isolates SN6 and SN7 by passages in cell culture. Veterinary Parasitology, 95(24), 155-166.

Dubey, J. P., Mitchell, S. M., Morrow, J. K., Rhyan, J. C., Stewart, L. M., Granstrom, D. E., Lindsay, D. S. (2003). Prevalence of antibodies to Neospora caninum, Sarcocystis neurona, and Toxoplasma gondii in wild horses from central Wyoming. Journal of Parasitology, 89(4), 716-720.

Dubey, J. P., Saville, W. J. A., Lindsay, D. S., Stich, R. W., Stanek, J. F., Speer, C. A., Shen, S. K. (2000). Completion of the life cycle of Sarcocystis neurona. Journal of Parasitology, 86(6), 12761280.

Dubey, J. P., Saville, W. J. A., Stanek, J. F., Lindsay, D. S., Rosenthal, B. M., Oglesbee, M. J., Kwok, O. C. H. (2001f). Sarcocystis neurona infections in raccoons (Procyon lotor): evidence for natural infection with sarcocysts, transmission of infection to opossums (Didelphis virginiana), and experimental induction of neurologic disease in raccoons. Veterinary Parasitology, 100(3-4), 117129.

Dubey, J. P., Venturini, M. C., Venturini, L., McKinney, J. \& Pecoraro, M. (1999b). Prevalence of antibodies to Sarcocystis neurona, Toxoplasma gondii and Neospora caninum in horses from Argentina. Veterinary Parasitology, 86(1), 59-62.

Fayer, R., Mayhew, I. G., Baird, J. D., Dill, S. G., Foreman, J. H., Fox, J. C., Sweeney, R. W. (1990). Epidemiology of equine protozoal myeloencephalitis in North America based on histologically confirmed cases: a report. Journal of Veterinary Internal Medicine, 4(2), 54-57.

Fenger, C. K., Granstrom, D. E., Gajadhar, A. A., Williams, N. M., McCrillis, S. A., Stamper, S., Dubey, J. P. (1997a). Experimental induction of equine protozoal myeloencephalitis in horses using Sarcocystis sp. sporocysts from the opossum (Didelphis virginiana). Veterinary Parasitology, 68(3), 199-213.

Fenger, C. K., Granstrom, D. E., Langemeier, J. L. \& Stamper, S. (1997b). Epizootic of equine protozoal myeloencephalitis on a farm. Journal of the American Veterinary Medical Association, 210(7), 923927.

Fenger, C. K., Granstrom, D. E., Langemeier, J. L., Stamper, S., Donahue, J. M., Patterson, J. S., Dubey, J. P. (1995). Identification of opossums (Didelphis virginiana) as the putative definitive host of Sarcocystis neurona. The Journal of parasitology, 81, 916-919. 
Granstrom, D. E., Alvarez Jr, O., Dubey, J. P., Comer, P. F. \& Williams, N. M. (1992). Equine protozoal myelitis in Panamanian horses and isolation of Sarcocystis neurona. The Journal of Parasitology, 78, 909-912.

Gupta, G. D., Lakritz, J., Kim, J.-H., Kim, D.-Y., Kim, J.-K. \& Marsh, A. E. (2002). Seroprevalence of Neospora, Toxoplasma gondii and Sarcocystis neurona antibodies in horses from Jeju island, South Korea. Veterinary Parasitology, 106(3), 193-201.

Hamir, A. N., Tornquist, S. J., Gerros, T. C., Topper, M. J. \& Dubey, J. P. (1998). Neospora caninumassociated equine protozoal myeloencephalitis. Veterinary Parasitology, 79(4), 269-274.

Hoane, J. S., Gennari, S. M., Dubey, J. P., Ribeiro, M. G., Borges, A. S., Yai, L. E. O., Howe, D. K. (2006). Prevalence of Sarcocystis neurona and Neospora spp. infection in horses from Brazil based on presence of serum antibodies to parasite surface antigen. Veterinary Parasitology, 136(2), 155159.

Hoane, J. S., Yeargan, M. R., Stamper, S., Saville, W. J., Morrow, J. K., Lindsay, D. S. \& Howe, D. K. (2005). Recombinant NhSAG1 ELISA: a sensitive and specific assay for detecting antibodies against Neospora hughesi in equine serum. Journal of Parasitology, 91(2), 446-452.

Howe, D. K., MacKay, R. J. \& Reed, S. M. (2014). Equine protozoal myeloencephalitis. Veterinary Clinics: Equine Practice, 30(3), 659-675.

Lindsay, D. S., Thomas, N. J. \& Dubey, J. P. (2000). Biological characterisation of Sarcocystis neurona isolated from a Southern sea otter (Enhydra lutris nereis). International Journal for Parasitology, 30(5), 617-624.

Marsh, A. E., Barr, B. C., Madigan, J., Lakritz, J., Nordhausen, R. \& Conrad, P. A. (1996). Neosporosis as a cause of equine protozoal myeloencephalitis. Journal of the American Veterinary Medical Association, 209(11), 1907-1913.

Mayhew, I. G. (1976). Equine protozoal myeloencephalitis. Proceedings of the Annual Convention of the American Association of Equine Practitioners, 22, 107-114.

McAllister, M. M., Dubey, J. P., Lindsay, D. S., Jolley, W. R., Wills, R. A. \& McGuire, A. M. (1998). Rapid communication: Dogs are definitive hosts of Neospora caninum. International Journal for Parasitology, 28(9), 1473-1479.

NAHMS. (2001). Equine Protozoal Myeloencephalitis (EPM) in the U.S. Fort Collins: APHIS: VS.

Pitel, P. H., Pronost, S., Romand, S., Thulliez, P., Fortier, G. \& Ballet, J. J. (2001). Prevalence of antibodies to Neospora caninum in horses in France. Equine Veterinary Journal, 33(2), 205-207.

Prickett, M. E. (1968). Equine spinal ataxia. Paper presented at the 14th Annual Convention of the American Association of Equine Practitioners, Philadelphia, USA.

Pusterla, N., Conrad, P. A., Packham, A. E., Mapes, S. M., Finno, C. J., Gardner, I. A., Wilson, W. D. (2011). Endogenous transplacental transmission of Neospora hughesi in naturally infected horses. The Journal of Parasitology, 97(2), 281-285.

Reed, S. M., Furr, M., Howe, D. K., Johnson, A. L., MacKay, R. J., Morrow, J. K., Witonsky, S. (2016). Equine protozoal myeloencephalitis: an updated consensus statement with a focus on parasite biology, diagnosis, treatment, and prevention. Journal of Veterinary Internal Medicine, 30(2), 491502.

Rooney, J. R., Prickett, M. E., Delaney, F. M. \& Crowe, M. W. (1970). Focal myelitis-encephalitis in horses. Cornell Veterinarian, 50, 494-501.

Roskov, Y., Kunze, T., Paglinawan, L., Orrell, T., Nicolson, D., Culham, A., Baillargeon, G. (2013). Species 2000 \& ITIS Catalogue of Life, 2013. Annual Checklist, 1, 1-2.

Saville, W. J., Morley, P. S., Reed, S. M., Granstrom, D. E., Kohn, C. W., Hinchcliff, K. W. \& Wittum, T. E. (2000a). Evaluation of risk factors associated with clinical improvement and survival of horses with equine protozoal myeloencephalitis. Journal of the American Veterinary Medical Association, 217(8), 1181-1185.

Saville, W. J., Reed, S. M., Granstrom, D. E., Hinchcliff, K. W., Kohn, C. W., Wittum, T. E. \& Stamper, S. (1997). Seroprevalence of antibodies to Sarcocystis neurona in horses residing in Ohio. Journal of the American Veterinary Medical Association, 210(4), 519-524. 
Saville, W. J., Reed, S. M., Morley, P. S., Granstrom, D. E., Kohn, C. W., Hinchcliff, K. W. \& Wittum, T. E. (2000b). Analysis of risk factors for the development of equine protozoal myeloencephalitis in horses. Journal of the American Veterinary Medical Association, 217(8), 1174-1180.

Saville, W. J. A., Sofaly, C. D., Reed, S. M., Dubey, J. P., Oglesbee, M. J., Lacombe, V. A., Shipley, R. D. (2004). An equine protozoal myeloencephalitis challenge model testing a second transport after inoculation with Sarcocystis neurona sporocysts. Journal of Parasitology, 90(6), 1406-1410.

Saville, W. J. A., Stich, R. W., Reed, S. M., Njoku, C. J., Oglesbee, M. J., Wunschmann, A., Granstrom, D. E. (2001). Utilization of stress in the development of an equine model for equine protozoal myeloencephalitis. Veterinary Parasitology, 95(2-4), 211-222.

Speer, C. A. \& Dubey, J. P. (2001). Ultrastructure of schizonts and merozoites of Sarcocystis neurona. Veterinary Parasitology, 95(2-4), 263-271.

Tillotson, K., McCue, P. M., Granstrom, D. E., Dargatz, D. A., Smith, M. O. \& Traub-Dargatz, J. L. (1999). Seroprevalence of antibodies to Sarcocystis neurona in horses residing in northern Colorado. Journal of Equine Veterinary Science, 19(2), 122-126.

Vardeleon, D., Marsh, A. E., Thorne, J. G., Loch, W., Young, R. \& Johnson, P. J. (2001). Prevalence of Neospora hughesi and Sarcocystis neurona antibodies in horses from various geographical locations. Veterinary Parasitology, 95(2-4), 273-282.

Villalobos, E. M. C., Furman, K. E., Lara, M. d. C. C., Hunold, S., Cunha, E. M. S., Finger, M. A., Dornbusch, P. T. (2012). Detection of Neospora sp. antibodies in cart horses from urban areas of Curitiba, Southern Brazil. Revista Brasileira de Parasitologia Veterinária, 21(1), 68-70.

Wendte, J. M., Miller, M. A., Lambourn, D. M., Magargal, S. L., Jessup, D. A. \& Grigg, M. E. (2010). Self-mating in the definitive host potentiates clonal outbreaks of the apicomplexan parasites Sarcocystis neurona and Toxoplasma gondii. PLoS Genetics, 6(12), e1001261.

Recebido: 12 dezembro, 2018.

Aprovado: 29 dezembro, 2018.

Publicado: 14 janeiro, 2019.

Licenciamento: Este artigo é publicado na modalidade Acesso Aberto sob a licença Creative Commons Atribuição 4.0 (CC-BY 4.0), a qual permite uso irrestrito, distribuição, reprodução em qualquer meio, desde que o autor e a fonte sejam devidamente creditados. 